\title{
The state of the Journal: A critique by the Editor
}

\author{
Lawrence H. Cohn, MD
}

As I write this editorial, we are coming to the end of 2011 and looking forward to a happy, healthy, and productive 2012.

The past year has seen some new developments in the Journal of Thoracic and Cardiovascular Surgery, which we believe has not only enhanced the quality of the JTCVS but also the entire profession of cardiothoracic surgery. No better example is the Cardiothoracic Surgical Education and Training section introduced in May 2011 under the capable direction of Ara Vaporciyan. Education and training at the resident and postgraduate level are crucial to the future of our specialty especially with reduced work hours. The purpose of this section is to highlight articles central to the evolution of thoracic and cardiovascular surgery as it relates to education and training, including the expanding interest in prospective randomized studies. As my mentor Dr Shumay used to say, "Nothing ever stays the same" and I believe this section is an important adjunct to that theory.

I would like to take this opportunity to emphasize the importance of continuing medical education (CME) credits. CME is obviously becoming increasingly important as maintenance of certification is now spreading throughout the world in cardiothoracic surgery. We are revamping our efforts to identify articles for CME credits. We will be adding a new decision term in the recommendation area of Editorial Manager, which will be "Accept with CME." This will generate a letter to the author requesting 4 to 7 questions of importance related to the article. Up to now, the responsibility of indentifying articles that are CME eligible lies with Dr Vaporciyan and with Dr Meyers before him; now all Associate Editors will be involved in the selection process. I can't emphasize enough the importance of these CME questions as well as the potential benefits to the author by being selected to provide these questions. I believe articles selected for CME credits will not only increase the visibility of the author but also the article. Our ability to provide excellent CME will not only increase our readership but also highlight the author and enhance the Journal.

Of interest as well is the Chinese edition of the Journal under the direction of Sheng-Shou Hu, MD, of Fuwai Hospital in Beijing. This quarterly circulation of the best articles printed in the JTCVS in the previous quarter has been

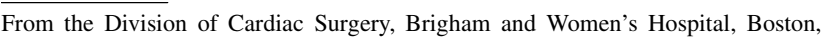
Mass.

Address for reprints: Lawrence H. Cohn, MD, Division of Cardiac Surgery, Brigham and Women's Hospital, 75 Francis St, Boston, MA 02115 (E-mail: lcohn@ partners.org).

J Thorac Cardiovasc Surg 2012;143:259

$0022-5223 / \$ 36.00$

Copyright (c) 2012 by The American Association for Thoracic Surgery doi:10.1016/j.jtcvs.2011.12.017
}

well received and we have received a request from the Chinese cardiothoracic community to expand the size and content of the Chinese edition to include commentaries by prominent Chinese surgeons as well as inclusion of select articles specifically pertaining to China and its current medical system. We are currently contemplating expanding into other non-English speaking countries of the world.

In an expanded effort to make articles in brief more relevant to our readership, we are introducing a new format. We feel the title Brief Communications, Clinical, Techniques, and Research does not provide justice to the actual articles. Going forward, Brief Clinical Reports will be retitled Case Reports and will be accepted for publication online only, allowing for a rapid turnover of these interesting reports; these will be referenced in the table of contents. Brief Technique Reports will now be titled Surgical Techniques and we continue to encourage submission of new surgical techniques that, when accepted, will be communicated to our readership in a rapid manner. Brief Research Reports are those of preliminary experimentation that show great promise, which we believe is extremely important to continue to highlight to our readership.

Back in July, we initiated a new format for the review of original manuscripts, which consists of 9 elements that, in our opinion, defines an outstanding paper. This metric system has increased the speed and quality of reviews while allowing us to continue to maintain our selection of outstanding articles. Further enhancements have been made to this review process to give the authors in-depth information to aid in the revision of their manuscripts based on these 9 elements.

Our Cardiothoracic Imaging section continues to be very popular and we encourage you to submit your outstanding images with a brief description so these may be highlighted in subsequent issues. Imaging is becoming an increasingly important aspect of cardiothoracic surgery and serves as an outstanding educational tool to residents and practitioners alike.

Finally, our long-time publisher, Josh Spieler, has been promoted and Elsevier has assigned us a new, extremely experienced publisher by the name of David Sampson. I would like to take this opportunity to thank Josh Spieler for the extraordinary efforts he put forward for many years that helped us to make the Journal the elite publication it is. Also, please join me in welcoming David Sampson. We look forward to a long and productive relationship.

Being the Editor can be challenging in this highly competitive literary environment as we strive to publish the best clinical and basic science articles in our field and I look forward to working with each and every one of you to continue to make the Journal of Thoracic and Cardiovascular Surgery the best in our field. 